\title{
DA AUTOGOVERNANÇA À DEPENDÊNCIA DO PODER PÚBLICO: O 'CIRCUITO ITALIANO DE TURISMO RURAL' NO MUNICIPIO DE COLOMBO (PARANÁ, BRASIL)
}

\author{
Clotilde Zai \\ Doutora pelo Programa de Pós-Graduação em Geografia \\ Universidade Federal do Paraná (UFPR) \\ Curitiba, PR, Brasil \\ clotildezai@yahoo.com.br \\ Cicilian Luiza Löwen Sahr \\ Professora do Programa de Pós-Graduação em Geografia \\ Universidade Estadual de Ponta Grossa (UEPG) \\ Ponta Grossa, Brasil. \\ cicilian@uol.com.br
}

\begin{abstract}
RESUMO
O turismo vem contribuindo para o desenvolvimento do entorno rural na Região Metropolitana de Curitiba, área de grande concentração urbana localizada no leste do estado do Paraná, Brasil. Roteiros turísticos rurais são os instrumentos utilizados para o fomento desse desenvolvimento. Analisa-se aqui a articulação entre roteirização turística e desenvolvimento territorial a partir da constituição de sistemas de autogovernança: as associações e os conselhos de roteiros. O aprofundamento empírico se volta ao 'Circuito italiano de turismo rural' no município de Colombo. A abordagem utilizada é qualitativa e se pauta em entrevistas de profundidade e observação in loco. Avalia-se o potencial natural e cultural explorado, as transformações ocorridas no sistema produtivo local e o processo de gestão do roteiro. O roteiro analisado, que tem Curitiba como principal público consumidor, apresenta-se como um exemplo de desenvolvimento territorial rural. Ele explora os potenciais da produção agrícola, das festas típicas, da gastronomia, da natureza e da arquitetura. Todavia, as dinâmicas autônomas vêm sendo gradativamente reduzidas, crescendo a dependência para com o poder público.
\end{abstract}

Palavras-chave: Turismo. Desenvolvimento. Região Metropolitana de Curitiba.

\section{FROM SELF-GOVERNMENT TO THE DEPENDENCY ON PUBLIC INSTITUTIONS: THE "ITALIAN ROUTE OF RURAL TOURISM" IN THE COLOMBO MUNICIPALITY (PARANÁ, BRAZIL)}

\begin{abstract}
Tourism has contributed to the development of the rural surroundings in the Metropolitan Region of Curitiba, a densely urbanized region located in the Eastern portion of Paraná State, Brazil. Rural touristic routes are tools to foment such a development. This article analyzes the articulation between touristic route planning and territorial development from a systemic perspective on self-government, exemplified through route associations. The empirical evidences were drawn from the "Italian route of rural tourism" in the Colombo Municipality. The approach is qualitative and based on in-depth interviews and local observations. Thus, it was investigated the natural and cultural potential, the transformations that have affected the local productive system and the process of route planning. Specifically, it analyzes the route, which mainly targets consumers from Curitiba, under the aspect of Rural Territorial Development. Here, the potential of agricultural production, ethnic festivals, gastronomy, nature and architecture, are important. However, the autonomous dynamics are gradually loosing force in benefit of an increasing dependency on public institutions.
\end{abstract}

Keywords: Tourism. Development. Metropolitan Region of Curitiba.

\section{INTRODUÇÃO}

O conceito 'desenvolvimento territorial' vem ganhando destaque tanto no debate científico como nas políticas públicas. A influência das discussões e experiências de outros países marca a atuação do

$\begin{array}{lllll}\text { Caminhos de Geografia } \quad \text { Uberlândia-MG } & \text { v. 23, n. } 85 & \text { fev./2022 } & \text { p. 102-114 Página } 102\end{array}$


Estado brasileiro e de atores locais na promoção desta tônica de desenvolvimento. Neste contexto, a roteirização turística torna-se um instrumento para a operacionalização deste, tornando-se fundamental o envolvimento dos atores locais em processos autogestionários.

Partindo desta concepção, o objetivo central da investigação é analisar a articulação entre roteirização turística e desenvolvimento territorial a partir da constituição de sistema de autogovernança - Associação e Conselho de Turismo - em roteiro do entorno rural da Metrópole de Curitiba, ao Leste do Paraná. A intenção é: a) analisar as transformações ocorridas no sistema produtivo local; b) avaliar o potencial natural e cultural no sistema de roteirização turística; e c) avaliar o processo de gestão ou governança do roteiro.

O roteiro escolhido para dar profundidade à análise é o 'Circuito italiano de turismo rural' 1 no Município de Colombo (FIGURA 1) no entorno da Metrópole de Curitiba. Sua organização deu-se a partir da articulação entre os empreendimentos turísticos já existentes, contando com a iniciativa da Prefeitura Municipal de Colombo (PMC) e com as parcerias da Coordenadoria da Região Metropolitana de Curitiba (COMEC), Empresa Paranaense de Assistência Técnica e Extensão Rural (EMATER), Paraná Turismo e Ecoparaná em 1999. Em 2006 oficializou-se a Associação dos Empreendedores do Circuito Italiano de Turismo Rural de Colombo (ECITUR) visando à autogestão do roteiro. Desde 2012, entretanto, esta encontra-se inativa, passando o roteiro a coordenação do poder público local.

Figura 1 - Colombo (PR): Localização do 'Circuito italiano de turismo rural', 2020.

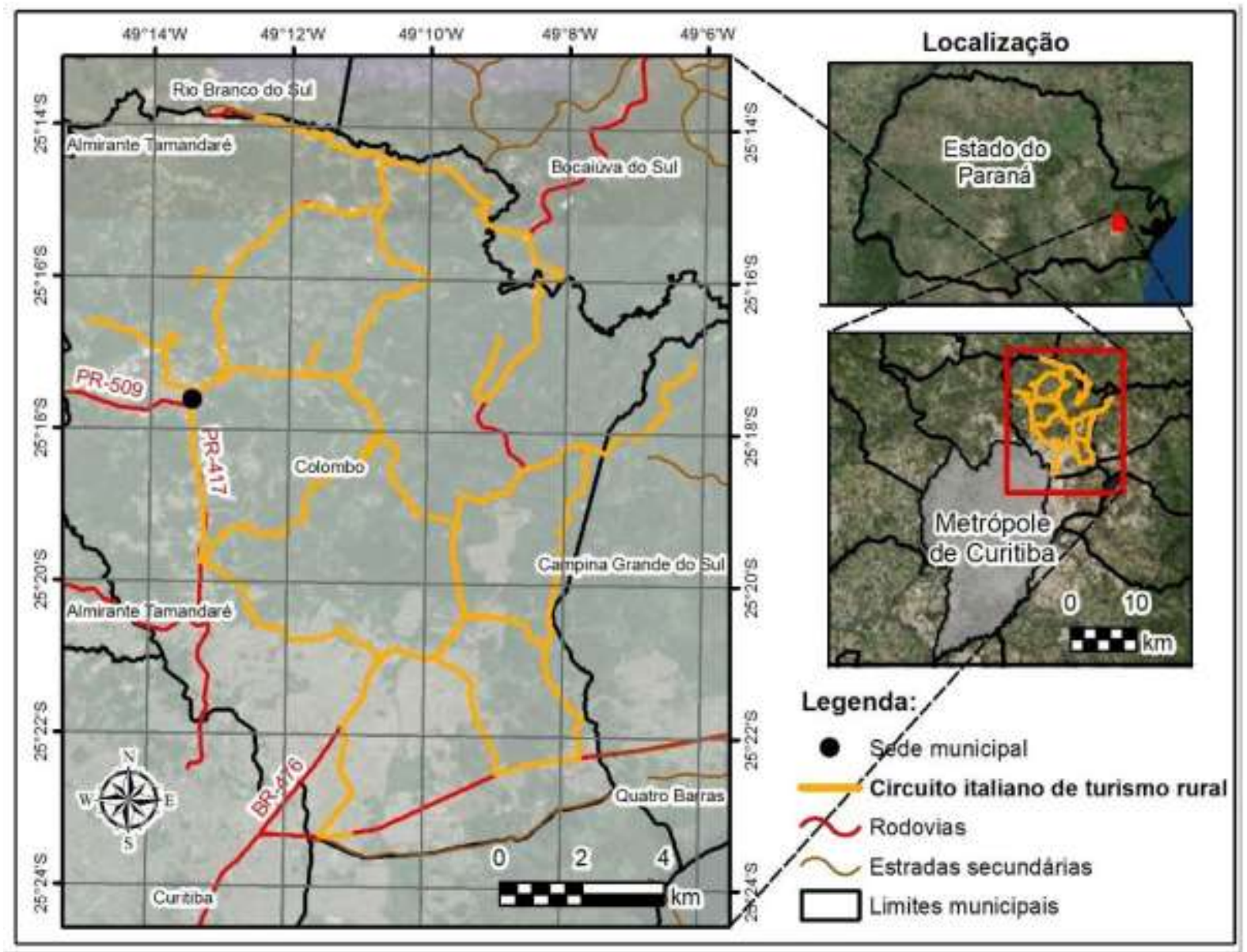

Fonte - ITCG (2015).

Org.: Autoras (2018); Silveira (2019).

${ }^{1}$ Outros roteiros do entorno rural de Curitiba são analisados em Zai (2019): 'Caminho do Vinho' e 'Circuito Rural Taquaral' no município de São José dos Pinhais, 'Turismo rural nas colônias polonesas' de Campo Largo e Campo Magro, 'Verde que te quero verde' de Campo Magro.

$\begin{array}{lllll}\text { Caminhos de Geografia } & \text { Uberlândia-MG } & \text { v. 23, n. } 85 & \text { fev./2022 } & \text { p. 102-114 Página } 103\end{array}$


Para a operacionalização da investigação e aproximação da realidade em estudo utilizou-se uma abordagem qualitativa. Inicialmente foram realizadas observações estruturadas (LAKATOS, MARCONI, 2003) através de visitações e conversas informais em atrativos e eventos do roteiro. $\mathrm{Na}$ sequência foram construídos roteiros de entrevistas com base na formatação teórica, ou seja, articulando os conceitos de roteirização turística, desenvolvimento territorial e governança.

As entrevistas em profundidade a partir dos roteiros construídos foram realizadas entre os anos 2016 e 2019 com representantes de diferentes grupos de interesse (QUADRO 1).

Quadro 1 - Colombo (PR): Caracterização dos entrevistados no roteiro turístico.

\begin{tabular}{|c|c|c|}
\hline Gênero & Função no roteiro & Identificação* $^{*}$ \\
\hline Masculino & Empreendedor (ECITUR) & ASS 1 \\
\hline Masculino & Empreendedor (ECITUR) & ASS 2 \\
\hline Feminino & Representante Poder Público (PMC) & PPL 1 \\
\hline Masculino & Visitante 1 \\
\hline Masculino & Visitante & VIS 2 \\
\hline \multicolumn{2}{|c|}{ Nota $-\left({ }^{*}\right)$ Foram ocultados os nomes, substituindo-os por siglas. } \\
\end{tabular}

Através de visitas ao roteiro e entrevistas com os atores foi possível elaborar um diagnóstico. A análise deste à luz de pressupostos teóricos compõe o presente artigo, que se estrutura em três partes. Inicia-se com uma discussão teórico-metodológica sobre roteirização turística e desenvolvimento territorial numa perspectiva autonomista. Prossegue-se com a apresentação do 'Circuito italiano de turismo rural', que é tomado como exemplo para a reflexão proposta. E, finaliza-se com a avaliação deste roteiro enquanto estratégia de desenvolvimento territorial.

\section{Roteirização turística e desenvolvimento territorial numa perspectiva autonomista}

O traçado de percursos orientados à atividade turística valoriza os potenciais atrativos e pode se converter em desenvolvimento territorial. Segundo Figueira (2013, p. 122), eles "implicam modificações e intrusões nas paisagens, quer pela reconversão de caminhos antigos em rotas turísticas, quer quando desenhados a propósito". Os atrativos constituem-se, portanto, em "espaços dispostos lateralmente ao eixo definido de cada percurso" (2013, p. 122) e possuem relevância na eficácia dos circuitos, pois se tornam alternativas de entretenimento para os visitantes.

Cooper, Hall e Trigo (2011, p. 21), defendem que a "imagem é decisiva para qualquer destino turístico" e, principalmente, para o seu marketing. Assim, através de um planejamento turístico territorializado, como no caso dos roteiros, torna-se possível unir esforços também em torno da comercialização do produto turístico, que agrega diferentes empreendimentos.

O território, segundo Souza (1995), é uma construção histórica e, por conseguinte, social. Nele se estabelecem relações de poder que envolvem ao mesmo tempo, sociedade e espaço geográfico. Neste contexto, tal conceito carrega o sentido de apropriação (simbólico) e domínio (concreto) de um espaço socialmente partilhado, como é o caso dos roteiros turísticos.

Silva (2006, p. 05) aprofunda a análise sobre a dimensão territorial no planejamento turístico comparando dois modelos. Para o autor, o Modelo do Polo de Crescimento, que inspira os "polos turísticos", privilegia os aspectos atrelados à função de especialização regional, ou seja, o turismo em si. Sua prática acontece ligada a investimentos exógenos que não empregam, numa escala otimizada, recursos produtivos de base local. Já o Modelo Territorialista recomenda a prevalência do território sobre a função, sendo considerado, portanto, mais adequado ao planejamento do desenvolvimento turístico por propiciar um efetivo grau de endogeneização dos benefícios socioeconômicos gerados no processo.

$\begin{array}{lllll}\text { Caminhos de Geografia } \quad \text { Uberlândia-MG } & \text { v. 23, n. } 85 & \text { fev./2022 } & \text { p. 102-114 Página } 104\end{array}$


Neste contexto, Silva (2006) demonstra que o Modelo Territorialista é mais apropriado para o desenvolvimento turístico. O território deve, portanto, prevalecer sobre a função turística que deverá incorporar. Dessa maneira, compreende-se que o turismo pode exercer um papel articulador e indutor do desenvolvimento, atuando de forma agregada e integrada com as demais atividades econômicas já existentes no território.

Para Meyer (2004) os roteiros de turismo que incorporam atrativos naturais e culturais podem cooperar para o desenvolvimento de comunidades marginalizadas. Essa contribuição advém da oferta de uma série de oportunidades, como o aumento da procura de bens e serviços, do número de empregos e renda, do lucro coletivo, da conservação e rejuvenescimento cultural e natural, bem como, da capacitação e desenvolvimento da infraestrutura.

Figueira (2013) complementa a abordagem de Meyer (2004) enfatizando que desenhar traçados inspirados na natureza, integrando atrativos em itinerários, promove o consumo turístico do espaço, bem como, da vida natural e cultural de cada destino. Dessa forma, roteiros contribuem para a troca de valores entre os turistas e a comunidade local, criam maiores e melhores fluxos turísticos, além de serem essenciais para a sustentabilidade econômica do turismo nas suas diferentes escalas territoriais.

Meyer (2004) defende que para a roteirização alcançar seus objetivos, são necessários os seguintes ingredientes: a) redes de cooperação, pensamento regional e liderança; b) desenvolvimento de produtos, infraestrutura e acesso; c) participação da comunidade, desenvolvimento de microempresas e inovação; d) informação e promoção; e) foco social aparente.

As relações entre redes de cooperação no âmbito do turismo vêm ganhando importantes contribuições, pois ponderam além do desenvolvimento local por meio de redes interorganizacionais, o aspecto regional. Ao se estabelecer um roteiro é fundamental manter acordos de colaboração entre o governo, o conselho local, as empresas privadas, as associações, a indústria do turismo e as comunidades locais. Segundo Meyer (2004, p. 16), "A cooperação é vista como o fator produtivo necessário e capaz de aproveitar as energias de todos os envolvidos com o desenvolvimento regional". Tem-se, assim, como benefício a criação de emprego e o consequente desenvolvimento territorial.

O estabelecimento de redes de colaboração é extremamente difícil, especialmente no ramo do turismo, que é caracterizado por uma infinidade de negócios de pequena escala com, diversas vezes, concorrentes metas e práticas operacionais (MEYER, 2004). Os atores municipais - poder público, empresários, sociedade civil e instituições de ensino - devem ser organizados em um ambiente denominado de "instância de governança regional" (MTUR, 2007a, p. 17), que pode ter diferentes formatos: fórum, conselho, associação, comitê ou outro tipo de colegiado. O objetivo principal da instância é reforçar a capacidade dos grupos para lidar com seus problemas, objetivos e metas, além de gerenciar seus recursos. Almeja-se, assim, um processo autonomista.

A autonomia está associada à ideia de liberdade, de ter escolha própria, da livre decisão dos indivíduos sobre suas ações e da possibilidade de traçar suas trajetórias de vida e assumir suas escolhas (FLEURY-TEIXERIA et al., 2008). Essa perspectiva se contrapõe a heteronomia, onde as normas e leis são elaboradas por terceiros (CAMPOS; CAMPOS, 2006).

Souza (2008, p. 61) associa a conceito de território à perspectiva de autonomia, apresentando-a de duas diferentes maneiras. A "autonomia individual" tem a ver com a capacidade do indivíduo de estabelecer fins para a sua própria existência e persegui-los com lucidez nos aspectos psicológicos, intelectual e social. A "autonomia coletiva" refere-se à presença de instituições sociais não heterônomas, mas delegadas, que garantam igualdade efetiva de oportunidades e satisfações de suas necessidades. Segundo o autor, "não há autonomia individual sem a coletiva: autonomia individual, sem autonomia pública é uma abstração individualista" (p.70).

Castoriadis (1996, p. 219) aponta a necessidade de uma articulação ética e política para "romper a barreira da heteronomia". Neste sentido, Souza (2008, p. 66) acredita que a ampliação da autonomia individual e coletiva possa ser o "caminho mais legítimo para melhoria na qualidade de vida e justiça social" na sociedade. A autonomia revela características das sociedades democráticas marcadas pelo direito à diversidade, livre expressão, liberdade de comportamentos tanto de indivíduos como de grupos, desde que respeitados os limites de prejuízos a terceiros.

$\begin{array}{llllll}\text { Caminhos de Geografia } & \text { Uberlândia-MG } & \text { v. 23, n. } 85 & \text { fev./2022 } & \text { p. 102-114 } & \text { Página } 105\end{array}$


Assim, as regras organizadas para o processo civilizatório emolduram e restringem a autonomia individual e coletiva. Numa sociedade, os diferentes grupos sociais gozam de diferentes graus de autonomia, o que demonstra a dimensão política da autonomia, uma vez que ela é consequência das relações de poder (CAMPOS; CAMPOS, 2006; FLEURY-TEIXEIRA et al., 2008).

Ao se pensar em uma "democracia participativa", ou seja, uma participação maior da população dentro da democracia representativa, Souza (2008, p. 202) sugere um grau de autonomia operacional, ainda que seja uma autonomia em longo prazo. Neste contexto, o autor sugere graus de "abertura para a participação popular" e apresenta uma escala de avaliação com oito categorias que vai da manipulação dos indivíduos e grupos do Estado ao controle cidadão (Quadro ).

Quadro 2 - Escala de avaliação: da não participação a participação autêntica.

\begin{tabular}{|c|c|c|c|}
\hline 1 & Coerção & Democracia representativa inexistente & \multirow{2}{*}{$\begin{array}{l}\text { Situações de não } \\
\text { participação }\end{array}$} \\
\hline 2 & Manipulação & População induzida e políticas compensatórias & \\
\hline 3 & Informação & Informação de intervenção - grau de transparência & \multirow{3}{*}{$\begin{array}{l}\text { Graus de } \\
\text { pseudoparticipação }\end{array}$} \\
\hline 4 & Consulta & População é consultada & \\
\hline 5 & Cooptação & $\begin{array}{l}\text { Cooptação de líderes - institucionalização de canais e } \\
\text { instâncias permanentes }\end{array}$ & \\
\hline 6 & Parceria & $\begin{array}{l}\text { Estado e sociedade civil colaboram com diálogo e } \\
\text { transparência }\end{array}$ & \multirow{3}{*}{$\begin{array}{l}\text { Graus de participação } \\
\text { autêntica }\end{array}$} \\
\hline 7 & $\begin{array}{l}\text { Delegação de } \\
\text { poder }\end{array}$ & $\begin{array}{l}\text { Estado abdica atribuições em favor da sociedade civil - } \\
\text { cogestão }\end{array}$ & \\
\hline 8 & Autogestão & Sociedade autônoma & \\
\hline
\end{tabular}

Assim, os graus 1 e 2 representam situações de não participação, enquanto os de 3, 4 e 5 revelam situações de uma sociedade heterônoma com elementos de pseudoparticipação. Já os graus 6,7 e 8 apresentam traços de planejamento e gestão democráticos. Acredita-se que as Associações e Conselhos de Turismo podem ser maneiras efetivas de participação popular no processo de gestão autônoma da roteirização turística. Dessa maneira, no tópico seguinte será apresentado um roteiro de turismo rural com a pretensão de analisar suas características em termos de desenvolvimento territorial e, consequentemente, de participação e/ou dependência do poder público.

\section{O 'Circuito italiano de turismo rural' como estudo empírico}

O 'Circuito italiano de turismo rural' abrange territorialmente todo o município de Colombo, estendendo-se para o município vizinho de Campina Grande do Sul. O roteiro passa pela sede urbana de Colombo, que dista aproximadamente $19 \mathrm{~km}$ de Curitiba. Várias opções de acesso estão disponíveis: a BR 116 (sentido São Paulo) corta a parte sul do município de Colombo ligando ao Oeste com os municípios de Campina Grande do Sul e Quatro Barras, onde situa-se a ligação com a Estrada da Graciosa e ao Sul (sentido Porto Alegre) com Curitiba; a BR 476, também conhecida como Estrada da Ribeira, corta o município ligando ao Norte com Bocaiúva do Sul e ao Sul ligando a BR 116 e Curitiba; a PR 417, mais conhecida como Rodovia da Uva, liga Colombo à Curitiba; e ainda a PR 509 ou Contorno Norte, que liga a Rodovia da Uva à PR 92 (Rodovia dos Minérios).

O sistema produtivo local, antes de se iniciarem os primeiros empreendimentos ligados ao turismo em Colombo, tinha por base atividades estritamente agrícolas. Alguns empreendedores turísticos ainda mantêm tais atividades, o que demonstra claramente as raízes e a manutenção da ruralidade no roteiro. As atividades turísticas, via de regra, se agregaram às atividades econômicas anteriormente desenvolvidas nas propriedades rurais. Há casos, todavia, em que estas foram mantidas apenas para consumo da própria família, passando o turismo a ser a principal atividade de renda. Há outros, entretanto, em que as atividades agrícolas foram totalmente abandonadas (PPL1, 2018; ASS2, 2018).

$\begin{array}{lllll}\text { Caminhos de Geografia } & \text { Uberlândia-MG } & \text { v. 23, n. } 85 & \text { fev./2022 } & \text { p. 102-114 Página } 106\end{array}$


Portanto, observa-se no roteiro a agregação de valor à propriedade rural propiciada pela atividade turística. A manutenção do sistema produtivo local, agregando a este as atividades turísticas, revela a preocupação de se utilizar o potencial endógeno da região na qual o roteiro se insere. Revela também o potencial articulador e indutor do turismo para o crescimento e desenvolvimento regional, que passa a atuar de forma integrada com as atividades econômicas pré-existentes.

Cada empreendimento teve, entretanto, iniciativa própria para abrir as portas na fase inicial, sem um planejamento coletivo prévio do roteiro. Um vitivinicultor e olericultor no roteiro, conta que a família dele sempre trabalhou com essa modalidade de produção desde que seus bisavós chegaram ao local vindos da Itália.

1890, quando os bisavós chegaram, já começaram produzir e vender vinho. Eu tenho um parreiral que meu nono trouxe da Itália a muda. Tem mais de 120 anos. Ele era baixinho e nós com o pai erguemos ele pra cima e fizemos uma esteira. Produz bem ainda (...). Aqui a vida inteira foi isso, só que chamávamos de 'vender vinho', geleia, suco e o pessoal chama de 'turismo rural' (ASS1, 2018).

Outro empreendedor conta que tem hoje um restaurante no circuito e afirma que a propriedade pertence à família há muitos anos. Conta que "a gente trabalhava com agricultura, mas o turismo já vinha se inserindo, pois antes de se trabalhar com restaurante a gente trabalhava com morango orgânico e recebia visitantes e escolas" para o turismo pedagógico (ASS2, 2018).

Há, portanto, indícios de que oferta turística tenha começado antes da existência do circuito. As primeiras reuniões para articulação do roteiro ocorreram entre 1997 e 1998, tendo este se consolidado apenas em 1999. A iniciativa das ações coletivas dos empreendedores não ocorreu apenas por iniciativa dos proprietários locais, contou com o apoio do poder público, portanto, foram sendo criadas redes de cooperação. A ECITUR foi instituída oficialmente apenas em 7 de junho de 2006 (PPL1, 2018; ASS2, 2018). A Associação não tinha uma sede fixa. As reuniões eram itinerantes e aconteciam nos empreendimentos dos associados, de forma alternada e sem a participação do poder público.

Com passar dos anos, todavia, a associação foi perdendo forças e houve desistência de participação de empreendedores, até o ponto de o presidente colocar seu cargo à disposição em 2012. Sem que ninguém manifestasse interesse em prosseguir com os trabalhos, a associação tornou-se inativa (ASS2, 2018). Desde então, o Conselho Municipal de Turismo é que coordena o Circuito. A presidência deste fica a cargo do poder público, do secretário municipal de Indústria, Comércio, Turismo e Trabalho. As reuniões não são sistemáticas, sendo marcadas quando surgem demandas (PPL1, 2018).

Os empreendimentos submetem seus projetos ao Conselho Municipal de Turismo. Estes são avaliados seguindo o Manual de Normas e Procedimentos Internos do Circuito. Os empreendimentos aprovados são inseridos ao roteiro, podendo instalar os totens padronizados, utilizar a marca, ficando autorizados a participar em projetos conjuntos como feiras e material de divulgação (PMC, 2018).

O potencial natural do município de Colombo tem forte apelo para a exploração turística. Grande parte de seu relevo é planáltico com predominância de morrotes e morros, colinas em menor escala. Ao norte do município apresentam-se cristas orientadas pelo controle estrutural com ocorrência de feições cársticas (BORTOLINI et al, 2018). Tais características geomorfológicas propiciam uma área com rico potencial natural que pode ser utilizado. O município abriga também o manancial subterrâneo do Carste na Bacia do Capivari, utilizado para abastecimento público de água. Ao Sudoeste do município encontra-se parte da Bacia do Canguiri, protegida pela Área de Proteção Ambiental do Iraí (PMC; UFPR, 2014).

O roteiro é, portanto, um exemplo de criação de imagem turística a partir de características endógenas naturais, mas também culturais e produtivas (QUADRO 3). Ele incorpora elementos das culturas italiana e polonesa dispostos no território, emaranhando a arquitetura, a religiosidade, os atrativos e a gastronomia. Elementos da agricultura familiar e da agroindustria existente também foram incorporados. Mesmo nos serviços de eventos e hospedagem há o esforço para que venham a fazer parte da imagem turística criada.

$\begin{array}{lllll}\text { Caminhos de Geografia } \quad \text { Uberlândia-MG } & \text { v. 23, n. } 85 & \text { fev./2022 } & \text { p. 102-114 Página } 107\end{array}$


Quadro 3 - Colombo (PR): Tipologia dos atrativos do 'circuito italiano de turismo rural'.

\begin{tabular}{|c|c|c|c|}
\hline Categoria & Tipo* $^{*}$ & Atrativos & ECITUR $^{\star \star}$ \\
\hline \multirow{2}{*}{$\begin{array}{l}\text { Naturais } \\
\text { (relevo) }\end{array}$} & Cárstico & Parque Municipal Gruta do Bacaetava & $\mathrm{X}$ \\
\hline & Continental & Morro da Cruz & $\mathrm{X}$ \\
\hline \multirow{9}{*}{ Culturais } & \multirow{3}{*}{$\begin{array}{l}\text { Arquitetura } \\
\text { Religiosa }\end{array}$} & Igreja São Pedro - Nossa Senhora do Caravaggio & $\mathrm{X}$ \\
\hline & & Casa da Memória da Venerável Irmã Antonieta Farani & $\mathrm{X}$ \\
\hline & & Igreja Matriz Paróquia Nossa Senhora do Rosário & $\mathrm{X}$ \\
\hline & Artístico & Casa da Cultura & $\mathrm{X}$ \\
\hline & \multirow{4}{*}{$\begin{array}{c}\text { Interesse } \\
\text { Cultural }\end{array}$} & Memorial do Imigrante Italiano - Casa Eugênio Mottin & $\mathrm{X}$ \\
\hline & & Memorial Ítalo-Polonês Famílias Perin e Puka & $\mathrm{X}$ \\
\hline & & Museu Municipal Cristóforo Colombo & $\mathrm{X}$ \\
\hline & & Grupo de Canto Luce Dell Anima & \\
\hline & Artesanato & La Casa Artesanato & $\mathrm{X}$ \\
\hline \multirow{29}{*}{$\begin{array}{c}\text { Serviços e } \\
\text { equipamentos }\end{array}$} & \multirow{4}{*}{ Hospedagem } & Hotel Capela do Atuba & \\
\hline & & Hotel Bolsi & \\
\hline & & Pousada Sítio da Alegria & \\
\hline & & Hotel Estância Betânia & \\
\hline & \multirow{13}{*}{$\begin{array}{l}\text { Alimentos e } \\
\text { Bebidas }\end{array}$} & Paladar Vinhos e Queijos & \\
\hline & & Franco Italiano Vinícola e Restaurante & $\mathrm{X}$ \\
\hline & & Pasárgada Restaurante Rural & $\mathrm{X}$ \\
\hline & & Restaurante e Churrascaria Berckemback I e II & \\
\hline & & Restaurante e eventos Bom Sabor & \\
\hline & & Restaurante Rural Bosque Italiano & $\mathrm{X}$ \\
\hline & & Restaurante Rural e Café Colonial É da Pam & $\mathrm{X}$ \\
\hline & & C.A.C. Chocolates Artesanais & $\mathrm{X}$ \\
\hline & & Vinícola Busato & $\mathrm{X}$ \\
\hline & & Vinícola Cavalli & $\mathrm{X}$ \\
\hline & & Vinícola Gasparin & $\mathrm{X}$ \\
\hline & & Vinícola Nobre Paladar & \\
\hline & & Vinícola Strapasson & $\mathrm{X}$ \\
\hline & \multirow[t]{2}{*}{ Agências } & CVC viagens & \\
\hline & & Guimatur & \\
\hline & \multirow{4}{*}{$\begin{array}{c}\text { Espaços de } \\
\text { Eventos }\end{array}$} & Sítio do Caqui - Salão do Lago & \\
\hline & & Deck Bolsi & \\
\hline & & Castelo Reale & \\
\hline & & Espaço Maydê - Ecopousada e Eventos Inspiradores & \\
\hline & \multirow{6}{*}{ Lazer } & Casalare del Nono & \\
\hline & & Pesque e Pague e Parque Aquático Sítio das Palmeiras & \\
\hline & & Pesque e Pague Do Tchê & $\mathrm{X}$ \\
\hline & & Pesque e Pague e Colha e Pague Gasparin e Filhos & $\mathrm{X}$ \\
\hline & & Pesque e Pague Morro das Pedras & \\
\hline & & Parque Municipal da Uva & \\
\hline Atividades & Agricultura & Chácara Gueno & $\mathrm{X}$ \\
\hline
\end{tabular}

$\begin{array}{lllll}\text { Caminhos de Geografia } \quad \text { Uberlândia-MG } & \text { v. 23, n. } 85 & \text { fev./2022 } & \text { p. 102-114 Página } 108\end{array}$




\begin{tabular}{|l|l|l|c|}
\hline Produtivas & $\begin{array}{c}\text { Familiar, } \\
\text { Agroindústria }\end{array}$ & Sítio Engenho Verde & $\mathrm{X}$ \\
\cline { 3 - 4 } & & Chácara Morango Natural & $\mathrm{X}$ \\
\cline { 3 - 4 } & & Sitio Mãe Terra & $\mathrm{X}$ \\
\cline { 3 - 4 } & Moinho Artesanal & $\mathrm{X}$ \\
\cline { 3 - 4 } & & Conservas Poli & \\
\hline
\end{tabular}

Nota - $\left(^{*}\right)$ Dados organizados com base na classificação de atrativos do MTur (2011).

$\left({ }^{* *}\right)$ Empreendimentos associados à ECITUR.

Fonte - PMC (2017), PPL1 (2018).

O 'Circuito italiano de turismo rural' recebe diversos eventos programados que fomentam a visitação (QUADRO 4). O maior e mais tradicional é a Festa da Uva, que teve sua primeira edição em 1959, idealizada pelo Pe. Geraldo Pelanda, com objetivo de incentivar o cultivo da uva e a produção do vinho no município (FERRARINI, 1992). Mais tarde, devido ao expressivo crescimento, a festa deixou de ser paroquial e foi assumida pela Prefeitura Municipal e realizada por meio de parcerias com agricultores, empresários, entidades de classe e comunidade em geral.

Quadro 4 - Colombo (PR): Calendário dos principais eventos no 'circuito italiano de turismo rural'.

\begin{tabular}{|l|l|l|}
\hline Evento & \multicolumn{1}{|c|}{ Mês } & \multicolumn{1}{|c|}{ Organização } \\
\hline Festa da Uva & Fevereiro & Prefeitura Municipal \\
\hline $\begin{array}{l}\text { Caminhada Internacional na Natureza - Circuito } \\
\text { Campestre }\end{array}$ & Abril & Depto Turismo \\
\hline Mostra de Turismo & Outubro & Depto Turismo \\
\hline Festa da Padroeira Nossa Senhora do Rosário & 07 de Outubro & $\begin{array}{l}\text { Paróquia Nossa Senhora do } \\
\text { Rosário }\end{array}$ \\
\hline Romaria Nossa Senhora do Caravaggio & 26 de Maio & Comunidade Capivari \\
\hline Missa no Morro da Cruz & 31 de Dezembro & Comunidade do Morro da Cruz \\
\hline Settimana Italiana & Agosto/Setembro & Associação Italiana \\
\hline
\end{tabular}

Fonte - PMC; UFPR (2014), PPL1 (2018).

As 'Caminhadas Internacionais na Natureza' até 2016 foram organizadas em dois circuitos: o Campestre em abril e o Imbuial Roseira em outubro. Ambos fomentados pelo Projeto Anda Brasil, coordenado pela Confederação Brasileira de Esportes Populares com o objetivo de fomentar a agricultura familiar, neste caso por meio do turismo rural (ANDA BRASIL, 2018). Segundo a representante do poder público entrevistada (PPL2, 2018), desde 2017 não é mais realizado o Circuito Roseira por se acreditar que sua região se "urbanizou muito e com isso perdeu a caracterização da caminhada". Já a do Circuito Campestre recebeu mais de 700 caminhantes em 2018. Ao final da caminhada, o participante pode optar por um almoço rural, adquirir produtos agrícolas e artesanato da região, ou ainda visitar os atrativos no roteiro.

Segundo a turismóloga entrevistada, também representante do poder público, há dificuldade de se cadastrar caminhadas no Anda Brasil sem a existência de uma Associação:

Pra você cadastrar uma caminhada no Anda Brasil tem que ser uma Associação, não pode mais ser a Prefeitura. A gente já até falou com pessoal do Bacaetava, pois lá temos uma concentração de empreendimentos, que se unam os empreendimentos e façam uma Associação. Aí a gente vai e ajuda montar o roteiro, essas coisas (PPL1, 2018). 
Outra questão apontada por essa representante do poder público é a desvinculação entre as caminhadas e a visitação ao roteiro:

O projeto é bem bacana e começou de um jeito bem bacana, o problema é que o pessoal que está indo caminhar agora, está vindo para caminhar mesmo, tanto que se fosse para conhecer o circuito levaria umas três horas, tem gente que faz em uma hora e meia. Caminha e vai embora. Não almoça na comunidade, não participa. (...). Então, (...) não sei até quanto que ela está ajudando a divulgar o turismo (PPL1, 2018).

Essa questão é um problema pontual de Colombo uma vez que outros roteiros já estudados revelaram as caminhadas como pontos fortes de chamariz para turistas e valorização das propriedades rurais (ZAI; LÖWEN SAHR, 2016, 2017).

Um caminhante entrevistado, que mora no município de Campo Largo, comentou que em vários dos roteiros em que fez caminhadas conheceu empreendimentos e voltou depois com a família. Ele, entretanto, fez uma crítica ao trajeto da caminhada em Colombo: "aqui não visitei porque não conheci nada, só andamos no meio da estrada, não passamos em nenhuma propriedade de turismo" (VIS1, 2018). Já um entrevistado de Curitiba, comentou que por meio das caminhadas conheceu três empreendimentos em Colombo (VIS2, 2018), revelando que alguns caminhantes visitam o roteiro por vontade própria, mesmo sem estímulo.

O Departamento de Turismo do município de Colombo vem trabalhando para melhorar e aumentar o público da 'Mostra de Turismo' que é realizada anualmente no mês de outubro:

\begin{abstract}
(...) ela é pequena, ainda não atrai um grande público de turistas, é mais a participação do pessoal da região, mas é uma feira que a gente fez pro pessoal divulgar e até mesmo se conhecer, pois muitas vezes o pessoal de Colombo não conhece os atrativos que tem aqui. Ano passado [2017] fizemos uma parceria com Departamento de Cultura com apresentações culturais. Junto com a Mostra de Turismo aconteceu também a Mostra de Artes e o Encontro de Violeiros. Reuniu aproximadamente 1200 pessoas, sendo que nas edições anteriores não tinha chegado a 300 pessoas (PPL1, 2018).
\end{abstract}

Outras entidades promovem eventos que fomentam a visitação no roteiro. Esse é o caso de algumas festas religiosas que tomaram grandes proporções. Entre as festas consolidadas estão: a) a Festa da Padroeira Nossa Senhora do Rosário, que está em sua 123르 edição e recebe em torno de 3.000 pessoas; b) a Romaria Nossa Senhora do Caravaggio, que está na $41^{\text {a }}$ edição e recebe em torno de 6.000 pessoas; e c) a Missa no Morro da Cruz, que acontece todo 31 de dezembro atraindo um público expressivo. As festas religiosas reúnem visitantes dos municípios de Colombo e do entorno (INVTUR, 2015, p.277). Além destas festas de grande porte, há também aquelas comunitárias de menor abrangência, mas igualmente importantes.

A 'Settimana Italiana' é um conjunto de eventos que ocorre geralmente no mês de agosto sendo organizado pela Associação Italiana Padre Alberto Casavecchia. A sua finalidade é difundir os vários aspectos da cultura italiana, tais como: gastronomia, religiosidade, canto, dança, jogos típicos e língua vêneta. Em 2019 foi realizada a 13a . Edição do evento com programação espalhada por comunidades tradicionais de Colombo (ASSOCIAÇẪO ITALIANA, 2019).

O município de Colombo se destaca também na área de esportes, recebendo atletas, em função de sua proximidade com Curitiba. Há diversos eventos esportivos programados como a $123^{a}$. edição da Corrida da Lua Cheia de Colombo, que é realizada em 12 etapas no Parque da Uva com organização do Click Corridas em parceria com a Secretaria Municipal de Esportes, Cultura, Lazer e Juventude da PMC. Ao que parece, entretanto, as secretarias municipais não tem uma sistemática de integração, pois o público que vem a Colombo para as atividades esportivas não é apresentado ao roteiro turístico ofertado pelo município. O único estabelecimento do roteiro conveniado à corrida é o Hotel Bolsi, que hospeda os atletas.

Um empreendedor do roteiro entrevistado afirma que os eventos trazem turistas para seu estabelecimento, principalmente os que vem para a Caminhada e para a Festa da Uva:

(...) Vem ônibus. Vem pra caminhada e passam aqui. Ligam e a gente atende. Quem vem na Festa da Uva conhece a vinícola lá e depois vem aqui. Na festa é uma propaganda boca a boca onde a pessoa fica conhecendo lá e depois vem aqui (ASS1, 2018). 
Já outro empreendedor entrevistado, relata que tanto a Mostra de Turismo quanto a Caminhada não influenciam no público de seu estabelecimento, mesmo o percurso desta passando em frente de seu estabelecimento e este sendo ponto de apoio (ASS2, 2018). Os inscritos na caminhada têm direito a um almoço e com isso eles não buscam restaurantes do roteiro.

A fala da representante do poder público municipal, entretanto, evidencia as dificuldades de manter o 'Circuito italiano de turismo rural' ativo:

Existe o Conselho Municipal, mas não é dos empreendedores. Como outros conselhos, o nosso é paritário - iniciativa privada com iniciativa pública. Quem é o presidente do conselho é o secretário e quem convoca e toca as reuniões do conselho é a Secretaria. A gente tem empreendedores do turismo dentro, mas a participação deles é mínima. O nosso conselho funciona, ele está ativo, mas muitas vezes a gente não tem reunião por falta de quórum e quando tem quórum a maioria dos participantes são (sic) do poder público. O conselho é consultivo deliberativo. Ele não funciona muito, mas a gente tenta manter (PPL1, 2018).

Conta um empresário e sócio inativo entrevistado, que o roteiro, por meio da PMC, já teve parcerias com várias entidades e que se promovem cursos de formação aos empreendedores (ASS2, 2018). A turismóloga, representante do poder público, aponta que:
Atualmente a Secretaria está com um programa da FIEP [Federação da Indústria do Estado do Paraná] de desenvolvimento econômico do município que envolve o turismo e outras áreas afins e com a universidade as parcerias são pontuais. A gente já teve pra fazer o Inventário Turístico, a UFPR [Universidade Federal do Paraná] veio e fez o inventário. Agora estamos fazendo um acordo com a Geografia da UFPR para implantar o Geoturismo, vamos usar o drone pra mapear (PPL1, 2018).

Segundo esta representante do poder público (PPL1, 2018), são desconhecidos outros estudos de viabilidade técnica do roteiro que tenham sido realizados ao longo dos anos. Tem-se apenas o Inventário da Oferta Turística e Diagnóstico Colombo (PMC; UFPR, 2014/2015), feito em parceria entre a PMC e a UFPR. Observa-se, portanto, a necessidade de se repensar o roteiro a partir do seu momento atual e com a participação efetiva de seus principais atores: os empresários locais.

Um elemento fundamental tanto na criação como na consolidação de roteiros de turismo é a questão da infraestrutura (MTUR, 2007b). São aparentes as transformações em termos de infraestrutura ocorridas no 'Circuito italiano de turismo rural' após a criação do Conselho Municipal de Turismo em 2002 e da SMICTT em 2013. O roteiro possui posto de Informações Turísticas na Rodovia da Uva para facilitar acesso dos turistas aos atrativos em funcionamento (PPL1, 2018).

A sinalização turística está atualmente em fase de implantação de novo projeto, como relata a representante do poder público entrevistada:

\begin{abstract}
A sinalização nossa está bem precária, o que tinha de sinalização foi arrancada, pois estava bem destruída. A gente está com projeto para implantar a sinalização. (...) Estamos trabalhando no projeto. Deve sair este ano. As antigas eram coloridas. As novas serão marrons no padrão do Ministério do Turismo, foi uma escolha dos empreendedores (PPL1, 2018).
\end{abstract}

A capacitação do pessoal envolvido nas atividades de turismo é a maior aliada na qualificação do roteiro e deve ser avaliada constantemente (MTUR, 2007b). Para dar qualidade e credibilidade a esse processo, é fundamental estabelecer parcerias entre os setores público e privado. A turismóloga, representante do poder público, acredita que através do Conselho de Turismo se salienta que há potencialidade para qualificar os empreendimentos que compõe o roteiro, bem como para agregar outras atividades da comunidade a ele, como é o caso da hotelaria (PPL1, 2018).

Um dos empreendedores no roteiro aponta que seu empreendimento teve uma significativa ampliação do espaço físico. Além de atender como restaurante rural e café colonial, ele passou a atender eventos com serviço completo de decoração e alimentação.

A gente expandiu bastante nos últimos anos, agora o objetivo é lotar com eventos, festas infantis, casamentos, aniversários de vovós, que tem muita procura. Pra casamento até que temos bastante já, cerca de 40 por ano, quase $100 \%$ dos sábados agendados para casamento (ASS2, 2018).

Há dificuldade na qualificação e diversificação dos produtos nos empreendimentos, segundo a representante do poder público. A Secretaria monta cursos como o de boas práticas alimentares,

$\begin{array}{lllll}\text { Caminhos de Geografia } \quad \text { Uberlândia-MG } & \text { v. 23, n. } 85 & \text { fev./2022 } & \text { p. 102-114 Página } 111\end{array}$


atendimento, inglês, empreendedorismo, mas tem baixa participação dos empreendedores. Segundo ela, alguns chegam a dizer que "já sabem tudo" (PPL1, 2018). Um dos empreendedores no roteiro comentou que em 2017 foram convidados a participar do curso de empreendedorismo oferecido pela Prefeitura Municipal, mas que não participaram. Revelou ainda que está fazendo a qualificação dos funcionários em atendimento por meio do Senac (Serviço Nacional de Aprendizagem) (ASS2, 2018).

A Prefeitura Municipal estimulou a realização de trocas de experiências vivenciais com integrantes de associações de outros roteiros da região para estimular as atividades da associação inativa. Foi ofertado transporte e ocorreram as visitações em três roteiros, porém não surtiu efeito positivo, pois os empreendedores comparavam o roteiro visitante com os visitados. "A ideia era tirar proveito da maneira de se organizar concretamente e não fazer uma cópia literal, por isso não foi proveitoso" (PPL1, 2018).

Sobre a mão de obra utilizada nos empreendimentos, todos os empreendimentos atuam com mão de obra familiar e a maioria destes emprega também mão de obra externa. Principalmente os restaurantes e chácaras de eventos funcionam com mão de obra mista e pagamento em diárias, visto que a maioria só atende aos finais de semana e feriados. Os atrativos públicos possuem funcionários mantidos pela prefeitura (PPL1, 2018).

A representante do poder público entrevistada relata que não ocorreram transformações nos empreendimentos individuais após a implantação da associação do roteiro, mas sim após a implantação da SMICTT (PPL1, 2018). Nota-se que a organização pública trouxe estímulos para que os empreendedores investissem e se preparassem para o turismo. Sobre a concorrência interna, foi apontado que "infelizmente existe concorrência entre alguns empreendimentos dentro do roteiro e não como parceiros" (PPL1, 2018). Um empreendedor entrevistado salientou, entretanto, que existem casos de empreendedores que se ajudam mutuamente (ASS2, 2018).

A exploração de atrativos naturais e culturais, a articulação com as atividades produtivas da agricultura familiar e agroindústria, a oferta de serviços e equipamentos, aliados aos eventos realizados, vem fomentando as atividades turísticas no município de Colombo nas últimas duas décadas. Assim, embora a governança do 'Circuito italiano de turismo rural' passe por problemas conjunturais no momento, percebem-se contornos do que se concebe como 'desenvolvimento territorial'.

\section{CONSIDERAÇÕES FINAIS}

A abordagem construída sobre o 'desenvolvimento territorial rural' por meio da roteirização turística se caracteriza por garantir a transformação produtiva de certas zonas rurais mantendo nelas seus moradores e, mais que isso, melhorando as condições e qualidade de vida desses. Assim, pode-se afirmar que a agregação de atividades de turismo ao sistema produtivo local de base agrícola permitiu ao 'Circuito italiano de turismo rural' tornar-se um instrumento indutor de desenvolvimento endógeno e territorial no município de Colombo. Tal indução se tornou viável, sobretudo, por sua localização estratégica no entorno da Metrópole de Curitiba, equilibrando oferta e demanda às atividades turísticas.

Neste contexto, o turismo rural articulado no 'Circuito italiano de turismo rural' se apresentou como um instrumento versátil de 'desenvolvimento territorial' à medida que dinamizou os potenciais da produção agrícola, das festas típicas, da gastronomia, da natureza e da arquitetura, agregando valor aos produtos e as propriedades rurais por meio de parcerias e qualificação dos empreendedores.

Neste processo, entretanto, a fragilidade no sistema de autogovernança do roteiro fez com que a coordenação do mesmo fosse repassada da Associação dos Empreendedores do Circuito ao Conselho Municipal de Turismo. Embora com características diferenciadas, tais governanças contribuiram para dar sequência à dinâmica produtiva instaurada, que articulou a economia de seu território para o turismo como mercado alternativo. A ampliação da dependência ao poder público, todavia, foi gradativamente desmobilizando o processo inicialmente desencadeado de autogestão, descaracterizando um componente central do 'desenvolvimento territorial'. O fortalecimento da organização dos empreendedores locais, entretanto, ainda pode ser garantido. Isso porque a roteirização turística se concretizou, neste caso, como uma prática articuladora de questões ambientais, socioculturais e econômicas em um contexto de mercado.

Caminhos de Geografia Uberlândia-MG $\quad$ v. 23, n. $85 \quad$ fev./2022 $\quad$ p. 102-114 Página 112




\section{AGRADECIMENTOS}

Agradecemos aos entrevistados pela acolhida e materiais fornecidos; ao Ricardo Michael Pinheiro Silveira pela confecção do mapa; ao Sr. Wolf-Dietrich Sahr pela tradução do título e resumo para o inglês e a Capes pela concessão de bolsa de pesquisa à primeira autora.

\section{REFERÊNCIAS}

ANDA BRASIL. Missão, Visão e Valores. Disponível em: http://www.andabrasil.com.br/\#. Acesso em: 03 mai de 2018.

BORTOLINI, W.; SILVEIRA, C. T.; SILVEIRA, R. M. P.; SILVA, J. M. F. Técnicas geomorfométricas para o mapeamento de padrões de relevo: aplicação nas cartas Curitiba e Cerro Azul, estado do Paraná. Revista do Departamento de Geografia da USP, v. 36, p. 15-32, 2018.

https://doi.org/10.11606/rdg.v36i0.144285

CAMPOS, R.T.O.; CAMPOS, G.W.S. Co-construção da autonomia: o sujeito em questão. In: CAMPOS, G.W.S. et al. Tratado de Saúde Coletiva. São Paulo: Hucitec, 2006. p.669-688.

CASTORIADIS, C. La montée de l'insignifiance: les Carrefours du labyrinthe. IV. Paris: Seuil, 1996, coll.

COOPER, C., HALL, C. M., \& TRIGO, L. G. G. Turismo Contemporâneo. Rio de Janeiro: Elsevier, 2011.

FERRARINI, S. O município de Colombo. Curitiba: Champagnat, 1992.

FIGUEIRA, L. M. Roteirização do turismo: Uma abordagem preliminar à "apresentação-interpretação" do território. Revista Turismo \& Desenvolvimento, n²0 de 2013.

FLEURY-TEIXEIRA, P. et al. Autonomia como categoria central no conceito de promoção de saúde. Ciência \& Saúde Coletiva, v.13, sup. 2, p. 2115-22, 2008. https://doi.org/10.1590/S1413$\underline{81232008000900016}$

LAKATOS, E. M.; MARCONI, M. de A. Fundamentos de metodologia científica. - 5. ed. - São Paulo: Atlas 2003.

MEYER, D. Tourism routes and gateways: key issues for the development of tourism routes and gateways and their potential for pro-poor tourism. London: Overseas Development Institute. 2004.

MTUr - MINISTÉRIO DO TURISMO. Coordenação Geral de Regionalização. Programa de Regionalização do Turismo - Roteiros do Brasil: Módulo Operacional 3: Institucionalização da Instância de Governança Regional / Ministério do Turismo. Secretaria Nacional de Políticas de Turismo. Departamento de Estruturação, Articulação e Ordenamento Turístico. Coordenação Geral de Regionalização. - Brasília, 2007a.

MTUr - MINISTÉRIO DO TURISMO. Coordenação Geral de Regionalização. Programa de Regionalização do Turismo - Roteiros do Brasil: Módulo Operacional 7 Roteirização Turística/ Ministério do Turismo. Secretaria Nacional de Políticas de Turismo. Departamento de Estruturação, Articulação e Ordenamento Turístico. Coordenação Geral de Regionalização. - Brasília, 2007b.

MTur - MINISTÉRIO DO TURISMO. Inventário da Oferta Turística. Brasília: Ministério do Turismo, 2011.

PMC - PREFEITURA MUNICIPAL DE COLOMBO. Encarte turístico. 2017

PMC - PREFEITURA MUNICIPAL DE COLOMBO. Regulamento para empreendimentos turísticos de Colombo / PR. Disponível em: http://turismo.colombo.pr.gov.br/download/regulamento-paraempreendimentos-turisticos.pdf. Acesso em: 16 abr. de 2018.

PMC - PREFEITURA MUNICIPAL DE COLOMBO; UFPR - UNIVERSIDADE FEDERAL DO PARANÁ. Inventário da oferta turística e diagnóstico Colombo - Pr. 2014.

SILVA J. A. S. A Dimensão Territorial no Planejamento do Desenvolvimento Turístico no Brasil: modelo do pólo de crescimento versus modelo territorialista e endógeno. Turismo em Análise, v. 17, n. especial, p. 5-23, janeiro 2006. https://doi.org/10.11606/issn.1984-4867.v17i3p5-23 
SOUZA, M. L. Mudar a cidade: uma introdução crítica ao planejamento e à gestão de urbanos. $5^{a}$. Edição. Rio de Janeiro; Bertrand Brasil, 2008.

SOUZA, M. L. O território: sobre espaço e poder, autonomia e desenvolvimento. In: CASTRO, I. et al. (org.) Geografia:conceitos e temas. Rio de Janeiro: Bertrand Brasil. 1995.

$\mathrm{ZAI}, \mathrm{C}$. Sistemas de roteirização turística e desenvolvimento territorial: o entorno rural do aglomerado urbano de Curitiba/PR. 273fls. Tese - Universidade Federal do Paraná, Setor de Ciências da Terra, Programa de Pós-Graduação em Geografia. Curitiba, 2019.

ZAI, C.; SAHR, C. L. L. 'Circuito Italiano de Turismo Rural' de Colombo/PR: Estratégia de desenvolvimento territorial? In: VIII CIETA - Congreso Iberoamenricano de Estudios Teritoriales y Ambientales, 2018, Foz do Iguaçu. Anais... Foz do Iguaçu: UNIOESTE, 2018.

Recebido em: 18/09/2020

Aceito para publicação em: 22/12/2020 